\title{
New colon anatomy-related ratios used to predict the course of colonoscopy in children
}

\author{
Sławomir Woźniak ${ }^{1, A-E}$, Tomasz Pytrus ${ }^{2, A-C, E, F}$, Marek Woynarowski, ${ }^{3, C, E, F}$, Bartosz Puła ${ }^{4, C, E, F}$, \\ Zygmunt Domagała',E,F, Barbara Iwańczak ${ }^{2, C, E, F}$ \\ ${ }^{1}$ Department of Human Morphology and Embryology, Division of Anatomy, Wroclaw Medical University, Poland \\ $22^{\text {nd }}$ Department and Clinic of Pediatrics, Gastroenterology and Nutrition, Wroclaw Medical University, Poland \\ ${ }^{3}$ Department of Gastroenterology, Hepatology and Immunology. The Children's Memorial Health Institute, Warszawa, Poland \\ ${ }^{4}$ Department of Hematology, Institute of Hematology and Transfusion Medicine, Warszawa, Poland \\ A - research concept and design; B - collection and/or assembly of data; C - data analysis and interpretation; \\ $D$ - writing the article; $E$ - critical revision of the article; $F$ - final approval of the article
}

\section{Address for correspondence}

Sławomir Woźniak

E-mail: slawomir.wozniak@umed.wroc.pl

Funding sources

None declared

Conflict of interest

None declared

Received on June 29, 2018

Reviewed on September 10, 2018

Accepted on February 18, 2019

Published online on April 19, 2019

Cite as

Woźniak S, Pytrus T, Woynarowski M, Puła B, Domagała Z, Iwańczak B. New colon anatomy-related ratios used to predict the course of colonoscopy in children. Adv Clin Exp Med. 2019:28(12):1627-1632. doi:10.17219/acem/104547

DOI

10.17219/acem/104547

\section{Copyright}

Copyright by Author(s)

This is an article distributed under the terms of the

Creative Commons Attribution Non-Commercial License

(http://creativecommons.org/licenses/by-nc-nd/4.0/)

\section{Abstract}

Background. In children, colonoscopy is a safe procedure, although it is more difficult to perform in patients whose body mass index (BMI) is under 25.

Objectives. The aim of the study was to establish the relationship between children's age, body mass and height and incomplete colonoscopies due to colon anatomy.

Material and methods. A retrospective evaluation of diagnostic endoscopies in 403 children aged 3-18 years (192 girls and 211 boys) was performed. New ratios were introduced: the incomplete colonoscopy anatomy-related ratio (ICAR) and the modified incomplete colonoscopy anatomy-related ratio (MICAR).

Results. The terminal ilium was not reached in 59 children: 27 girls and 32 boys (14.6\% of patients). In 13 girls and 18 boys (comprising 7.69\% of the study population) no pathological causes were found for the incomplete colonoscopy. There were statistically significant differences concerning colon anatomy-related incomplete colonoscopies in relation to the children's weight. No significance was found in relation to height or age. Incomplete examinations were more frequent in patients weighing less than $30 \mathrm{~kg}(p=0.0006)$, both in boys $(p=0.0090)$ and girls $(p=0.048)$. The risk of incomplete colonoscopy (odds ratio $-0 R$ ) in boys and girls weighing less than $30 \mathrm{~kg}$ was $3.995(95 \% \mathrm{Cl}=1.489-10.720)$ and $3.373(95 \% \mathrm{Cl}=1.078-10.560)$, respectively. For this group of patients, the ICAR ranged between 0.0309 and 0.1889 , while the MICAR range was $0.0-0.1889$.

Conclusions. Body mass is a statistically significant factor for evaluating the risk of incomplete colonoscopies in children. The lower the ICAR and MICAR values, the lower the risk of non-completion of a colonoscopy due to anatomical (i.e., disease-unrelated) causes.

Key words: pediatric colonoscopy, incomplete colonoscopy, colon anatomy-related incomplete colonoscopy 


\section{Introduction}

The large intestine (LI) is evaluated using various diagnostic methods, ${ }^{1}$ and data defining the colon provided by different authors can differ to a great degree. ${ }^{2,3}$

The number of flexures in the LI is usually 9-10, but it may be as high as 19. ${ }^{2,4,5}$ The right colic flexures (RCF), left colic flexures (LCF) and the descending-sigmoid flexure (DSF) constitute sections with significantly limited mobility. Due to their attachment to the mesentery, the transverse colon (TC) and the sigmoid colon (SC) are the most movable sections. We refer to such segments as critical points (CPs). Previously published papers have provided a detailed assessment of the morphology of the entire LI, the mesentery and an analysis of position alterations of selected CPs (e.g., the RCF, LCF and DSF) in relation to the abdominal cavity, secondary to changes in body position. ${ }^{6,7}$ The entire length of the LI is $56.5 \pm 2.7 \mathrm{~cm}$ in infants, $107.8 \pm 4.5 \mathrm{~cm}$ in 2-year-olds, $122.4 \pm 5.7 \mathrm{~cm}$ in 5 -yearolds, and up to $180-190 \mathrm{~cm}$ in adults. ${ }^{3,5,7}$

Optical colonoscopy is the gold standard for the evaluation of the colon. ${ }^{2,8}$ One of the quality parameters of endoscopy is intubation of the terminal ileum (TI) through the ileocecal valve. ${ }^{9-12}$ Inserting the endoscope into the cecum is recommended in $\geq 90 \%$ of routine examinations and in $\geq 95 \%$ of screening examinations. ${ }^{13,14}$ Difficulties associated with the insertion of the endoscope can be overcome by maneuvers such as changing the patient's position or pressing the patient's abdominal wall. If these techniques fail, another colonoscope or a gastroscope may be used. ${ }^{15-17}$

One of the indirect parameters related to insertion difficulties and the anatomic complexity of the LI is the time needed to reach the cecum. ${ }^{18-20}$ Previous research has analyzed in particular the relationship between colonoscopic difficulties and the patients' gender, age, body mass and height, body mass index (BMI), waist circumference, and intra-abdominal fat. ${ }^{6,15,18-21}$ Complications related to instrument insertion, including intestinal perforation, occur in only a minor percentage of patients. ${ }^{22,23}$

The aim of this study was to establish the relationships between the age, body mass and height of the children and incomplete colonoscopies due to colon anatomy-related difficulties.

\section{Material and methods}

The paper is based on a 5-year retrospective observational study (2012-2016), performed according to the Declaration of Helsinki and approved by the Wroclaw Medical University Bioethics Committee (resolution No. 667/2017). The colonoscopies were performed under general anesthesia at the $2^{\text {nd }}$ Pediatrics, Gastroenterology and Nutrition Department at Wroclaw Medical University, Poland. The colonoscopic examinations were performed in the same conditions (between 8 a.m. and 2 p.m., in the same lab with the same personnel and equipment). All the examinations were performed by 2 specialists in gastroenterology with more than 10 years of experience in endoscopy, both holding the Polish Society of Gastroenterology Certificate of Advanced Skills in Colonoscopy.

The study included 403 children (192 girls and 211 boys) aged from 3 to 18 years. The body mass of the patients ranged between $12 \mathrm{~kg}$ and $92 \mathrm{~kg}$, and the body height was between $92 \mathrm{~cm}$ and $188 \mathrm{~cm}$. Every child's weight and height were measured on the day of colonoscopy. The preparation of the LI was either very good or good (8-9 points according to the Boston Bowel Preparation Scale).

Indications for the examination included inflammatory bowel disease (IBD) in 290 cases (199 follow-up examinations to assess current disease activity and 91 cases of suspected IBD), and gastrointestinal bleeding in the remaining 113 cases.

Written informed consent of the parent or legal guardian was obtained before the examination. The colonoscopies were performed with Olympus CFQ 165 L and PCF 160 AL colonoscopes (Olympus Corp., Tokyo, Japan) and the Pentax EC 3840MK2 colonoscope (Pentax Medical, Tokyo, Japan). The small number of examinations ensured that there was no wearing or tearing of scopes in the period analyzed. The patients' medical history was obtained, including past abdominal surgery. Typical pre-exam preparations involved purging with macrogol (Fortrans ${ }^{\circledR}$; Ipsen Pharma, Paris, France), dosed according to body mass, orally or via a gastric tube; additionally, on the preceding day and the examination day, enemas were performed with solutions of hydrogen phosphates (Enema ${ }^{\circledR}$; Laboratorium Galenowe Olsztyn, Olsztyn, Poland, or Rectanal ${ }^{\mathbb{R}}$; Farmaceutyczno-Chemiczna Spółdzielnia Pracy Galenus, Warszawa, Poland). In the case of 24 children over the age of 15, an oral phosphate product was used (Fleet Phosphosoda $^{\circledR}$; Labarotorios Casen-Fleet S. L., Zaragoza, Spain).

An examination in which the colonoscope reached the TI was considered a complete colonoscopy (CC); if the colonoscope did not reach the TI, the examination was regarded as an incomplete colonoscopy (IC). The ICs were divided into 2 subgroups: incomplete pathological colonoscopies (IPCs) and incomplete anatomy-related colonoscopies (IACs). Incomplete pathological colonoscopies were primarily caused by major inflammatory changes in the LI, posing a risk of perforations; IACs were those involving unusual LI anatomy or unknown causes.

The data obtained were used to calculate 2 ratios that estimate the risk of performing an incomplete colonoscopy for non-pathological causes (anatomic or unknown) in children with specific characteristics, e.g., age, body mass or height. We retrospectively calculated these indices (i.a., related to complex bowel anatomy and the given technical scope of the examiner) for our study cohort in order to apply them in subsequent examinations of children with similar demographic parameters. 


\section{The incomplete colonoscopy anatomy-related ratio (ICAR)}

\author{
$\mathrm{ICAR}=\mathrm{IAC}: \mathrm{CC}$
}

where IAC is the number of incomplete colonoscopies with anatomical or unknown causes and CC is the number of complete colonoscopies. The smaller the value of the index, the higher the chance of performing a complete colonoscopy. For example, if a single IAC occurred in a group of 100 examined children aged $\mathrm{X}$, the calculated index value would be 0.01 . This value means that in a given lab, it is to be expected that an examination will fail for anatomical or unknown reasons in 1 future case out of 100 .

\section{The modified incomplete colonoscopy anatomy-related ratio (MICAR)}

The second ratio refers to the reducing possibility of not completing the examination due to anatomical reasons after reaching subsequent CPs.

$$
\operatorname{MICAR}_{(\mathrm{CP})}=\mathrm{IACCP}: \mathrm{CC}
$$

where IACCP is the number of incomplete colonoscopies (for anatomical or unknown reasons) that occurred before a particular analyzed CP, and CC is the number of complete colonoscopies. The IACCP is calculated by subtracting the number of examination interruptions at CPs already passed by the colonoscope from the total number of IACs. Assuming hypothetically that 100 examinations were performed in a cohort with certain demographic characteristics, of which 5 were ended at the splenic flexure and 4 at the hepatic flexure (a total of 9 incomplete exams), then as the scope approaches the splenic flexure the value of the index is 0.09; after it passes the LCF, the index drops to 0.04 ; after it passes the RCF, the index drops to 0.0 . The index value indicates that in subsequent examinations, the risk of discontinuation at the LCF is 9 in 100, while after passing the LCF, it falls to 5 in 100, and after passing the RCF, there is no risk that the examination will be discontinued.

The ICAR is a fixed value for a given patient group, while the MICAR reflects the risk of non-completion decreasing as the scope passes subsequent bowel segments and flexures. We define difficult colon anatomy as a complicated 3D structure that causes an incomplete colonoscopy because of its flexures and/or atypical mesenteries.

\section{Statistical analysis}

The statistical analysis was carried out using STATISTICA v. 12 software (StatSoft Inc., Tulsa, USA). The $\chi^{2}$ test and Fisher's exact test were used for qualitative data analysis. Relevant confidence intervals were estimated (95\% CI). Relative risk (RR), sensitivity and specificity of the parameters studied were determined. The significance level for the study was $\mathrm{p}<0.05$.

\section{Results}

In 290 cases the examination confirmed IBD, while in the remaining 113 children the causes were as follows: 34 cases of gastrointestinal tract infections (among them Campylobacter, Yersinia or Clostridium); 10 cases of Meckel's diverticulum (the patients had isotope scans; 8 children underwent surgery, while the symptoms of the other 2 subsided with conservative management); 5 cases of isolated rectal ulcers; 8 cases of familial polyposis; 8 cases of polyps unrelated to polyposis; and in the remaining 48 cases, the cause of the presenting complaints remained unidentified. Some of these 48 children suffered from chronic constipation and we presume that the bleeding was related to lesions in the sphincter area (the bleeding coincided with the passing of stool). Some of the patients underwent magnetic resonance (MR) enterography due to suspected small bowel hemorrhage, but the examinations failed to provide a final diagnosis. The colonoscopy results are shown in Fig. 1.

In 15 of the IACs, the colonoscopy stopped at the RCF; in 13 at the LCF; and in 3 in the TC. None of the endoscopic examinations were interrupted in the SC or at the DSF. The detailed demographics of the children with IACs are shown in Table 1.

In the statistical analysis, the $X^{2}$ test showed that ICs were more frequent in children weighing less than $30 \mathrm{~kg}$ $(\mathrm{p}=0.0006)$, both in boys $(\mathrm{p}=0.009)$ and in girls $(\mathrm{p}=0.048)$.

The risk of an IC (the odds ratio - OR) in patients weighing less than $30 \mathrm{~kg}$ was 3.995 (95\% CI = 1.489-10.720) and 3.373 (95\% CI $=1.078-10.560)$ in boys and girls, respectively. There were no statistically significant relationships between the completion of the examination and the gender, height or age of the patients.

We used the ICAR and MICAR to explore the relationships between incomplete colonoscopies due to anatomical or unknown causes and the total number of colonoscopies in the examined groups. The calculated values of the ICAR

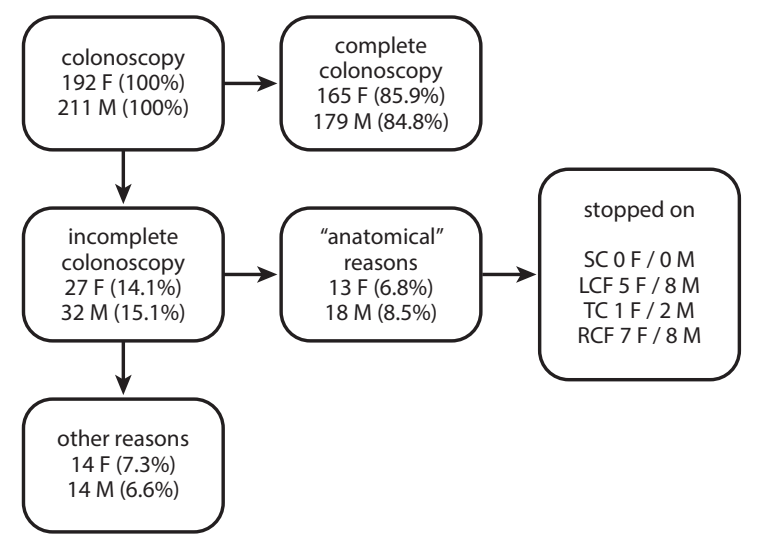

Fig. 1. Colonoscopy results

SC - sigmoid colon; LCF - left colic flexure; TC - transverse colon; $\mathrm{RCF}$ - right colic flexure. 
Table 1. Incomplete colonoscopies in relation to the demographics of the children

\begin{tabular}{|c|c|c|c|c|c|c|c|c|}
\hline \multirow{2}{*}{\multicolumn{2}{|c|}{ Demographics }} & \multirow{2}{*}{$\begin{array}{l}\text { Number } \\
\text { of patients }\end{array}$} & \multicolumn{2}{|c|}{ LCF } & \multicolumn{2}{|c|}{$\mathrm{TC}$} & \multicolumn{2}{|c|}{$\mathrm{RCF}$} \\
\hline & & & $F$ & $M$ & $F$ & $M$ & $F$ & $M$ \\
\hline \multirow{4}{*}{ Age [years] } & $\leq 6$ & 47 & 2 & 3 & 0 & 0 & 0 & 0 \\
\hline & $7-10$ & 78 & 0 & 3 & 1 & 1 & 1 & 0 \\
\hline & $11-14$ & 127 & 2 & 1 & 0 & 1 & 2 & 3 \\
\hline & $15-18$ & 151 & 1 & 1 & 0 & 0 & 4 & 5 \\
\hline \multirow{5}{*}{ Body height $[\mathrm{cm}]$} & $\leq 120$ & 43 & 1 & 2 & 0 & 0 & 0 & 0 \\
\hline & $121-130$ & 55 & 1 & 2 & 1 & 0 & 1 & 1 \\
\hline & $131-140$ & 78 & 1 & 1 & 0 & 0 & 2 & 2 \\
\hline & $141-150$ & 108 & 1 & 1 & 0 & 1 & 2 & 2 \\
\hline & $\geq 151$ & 119 & 1 & 2 & 0 & 1 & 2 & 3 \\
\hline \multirow{4}{*}{ Body mass [kg] } & $\leq 30$ & 109 & 4 & 6 & 1 & 2 & 2 & 2 \\
\hline & $31-50$ & 104 & 1 & 1 & 0 & 0 & 2 & 2 \\
\hline & $51-70$ & 108 & 0 & 1 & 0 & 0 & 1 & 1 \\
\hline & $\geq 71$ & 82 & 0 & 0 & 0 & 0 & 2 & 3 \\
\hline
\end{tabular}

LCF - left colic flexure; RCF - right colic flexure; TC - transverse colon; F - female; $M$ - male.

Table 2. Values of ICAR and MICAR in relation to the demographics of the children examined (both genders)

\begin{tabular}{|c|c|c|c|c|c|c|c|}
\hline \multicolumn{2}{|c|}{ Demographics } & Number of patients & ICAR & $\mathrm{MICAR}_{\mathrm{DSF}}$ & $\mathrm{MICAR}_{\mathrm{LCF}}$ & $\mathrm{MICAR}_{\mathrm{TC}}$ & MICAR $_{\text {RCF }}$ \\
\hline \multirow{4}{*}{ Age [years] } & $\leq 6$ & 47 & 0.1250 & 0.1250 & 0.1250 & 0.0 & 0.0 \\
\hline & $7-10$ & 78 & 0.0895 & 0.0895 & 0.0895 & 0.0448 & 0.0149 \\
\hline & $11-14$ & 127 & 0.0818 & 0.0818 & 0.0818 & 0.0545 & 0.0454 \\
\hline & $15-18$ & 151 & 0.0866 & 0.0866 & 0.0866 & 0.0709 & 0.0709 \\
\hline \multirow{5}{*}{ Body height $[\mathrm{cm}]$} & $\leq 120$ & 43 & 0.0857 & 0.0857 & 0.0857 & 0.0 & 0.0 \\
\hline & $121-130$ & 55 & 0.1304 & 0.1304 & 0.1304 & 0.0652 & 0.0435 \\
\hline & $131-140$ & 78 & 0.0882 & 0.0882 & 0.0882 & 0.0588 & 0.0588 \\
\hline & $141-150$ & 108 & 0.0737 & 0.0737 & 0.0737 & 0.0526 & 0.0421 \\
\hline & $\geq 151$ & 119 & 0.09 & 0.09 & 0.09 & 0.06 & 0.05 \\
\hline \multirow{4}{*}{ Body mass [kg] } & $\leq 30$ & 109 & 0.1889 & 0.1889 & 0.1889 & 0.0778 & 0.044 \\
\hline & $31-50$ & 104 & 0.0652 & 0.0652 & 0.0652 & 0.0435 & 0.435 \\
\hline & $51-70$ & 108 & 0.0309 & 0.0309 & 0.0309 & 0.0206 & 0.0206 \\
\hline & $\geq 71$ & 82 & 0.0769 & 0.0769 & 0.0769 & 0.0769 & 0.0769 \\
\hline
\end{tabular}

ICAR - incomplete colonoscopy anatomy-related ratio; MICAR - modified incomplete colonoscopy anatomy-related ratio; LCF - left colic flexure; $\mathrm{RCF}$ - right colic flexure; DSF - descending-sigmoid flexure; TC - transverse colon; F - female; $M$ - male.

and MICAR in individual patient groups are presented in Table 2.

The ICAR and MICAR are shown in Fig. 2. We present only the data for children weighing no more than $30 \mathrm{~kg}$, since the results for this group were statistically significant.

\section{Discussion}

The majority of the children examined suffered from IBD, which, paradoxically, may facilitate performing colonoscopies due to the rigidity of the gastrointestinal wall observed in such patients.

The ICAR and MICAR may be easier to understand for a child's parents than RR and OR. These ratios are easy to calculate and help evaluate the risk of IACs in the future on the basis of retrospective data. It is important to use these ratios together, i.e., to assess the combined risk of IACs for the age, body mass and height of a child. In our group of patients, the MICAR is equal to the ICAR up to the LCF, because none of the examinations were interrupted in the $\mathrm{SC}$, which is in contrast with other studies, which describe the $\mathrm{SC}$ as being more complex from an anatomical point of view. ${ }^{2,4}$

In this paper we are reporting the ICAR and MICAR for the first time. Therefore, we do not suggest reference ranges. No prior study has attempted to estimate correlations between the assessed demographic parameters of pediatric subjects and the causes of incomplete colonoscopy unrelated to disease. Madiba et al. found that the SC is significantly 


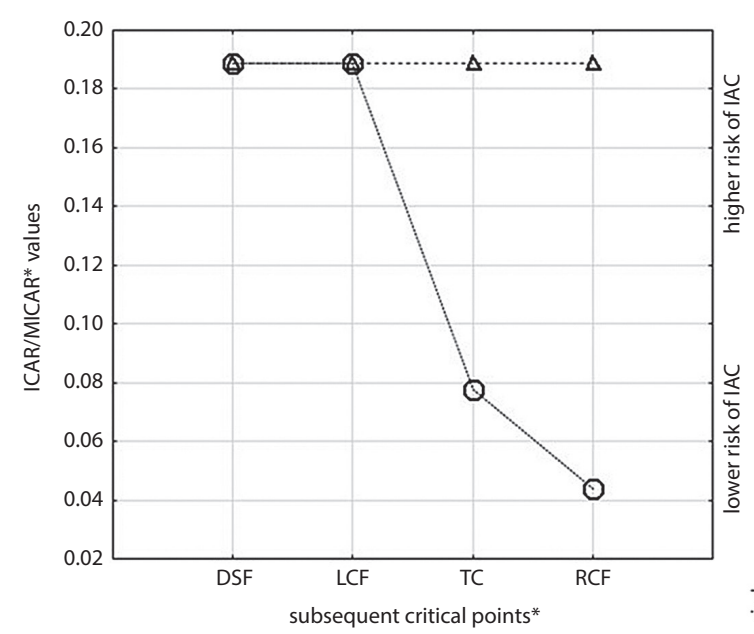

Fig. 2. ICAR/MICAR values at consecutive critical points

ICAR - incomplete colonoscopy anatomy-related ratio; MICAR - modified incomplete colonoscopy anatomy-related ratio; DSF - descendingsigmoid flexure; LCF - left colic flexure; TC - transverse colon; RCF - right colic flexure.

elongated in adults. ${ }^{24,25}$ In our opinion, the SC may adapt its structure (length in particular) to the digestive lifestyle of the patients (for example, different defecation frequencies or stool volumes). The SC is longer in Africans, whereas their mesentery is comparatively narrower; older age is associated with an elongation of the entire colon, reduced elasticity of the colon wall and an increase in colon laxity. ${ }^{26}$ However, in the present study, we cannot compare properties of the bowel (length and number of flexures) in the respective groups (defined by age, body mass and height) and their relationship with failed colonoscopies.

Elongation of the colon and/or complex colonic anatomy may be reflected in an increase in the time required to insert the colonoscope into the cecum. Hsieh et al. reported that time to be longer in women. ${ }^{19}$ Sadahiro et al. demonstrated that elongation of the LI occurred along with increases in body mass and height; however, this correlation was not found in males. ${ }^{26}$ This hypothesis was not confirmed by the results of our study. Other authors have also found no differences between the genders. ${ }^{24,25,27}$

Other authors have demonstrated a relationship between $\mathrm{BMI}$ and the duration of a colonoscopy. ${ }^{28}$ There is more intra-abdominal fat in obese patients, which contributes to the rigidity of the mesentery; therefore, the possibility of the endoscope looping is reduced to a minimum. In addition, obese or overweight adults are reported to have shorter colons. ${ }^{5}$ Our findings confirm this observation: In the present study there were more complete colonoscopies in heavier $(>30 \mathrm{~kg})$ patients than in lighter ones.

Our results may also confirm the observations of Hsieh et al., who indicated that waist circumference (larger waist circumference associated with a shorter insertion time) is the most important factor for a prognosis of difficulties with endoscope insertion. ${ }^{19}$ Hanson et al. stated that ICs are more frequent in patients with BMIs $<25 .{ }^{4}$ Other authors agree with the idea of the significance of body fat for the performance of endoscopies. ${ }^{2,18,20}$ In our group, a substantial proportion of patients demonstrated varying degrees of undernourishment due to their underlying disease, which also contributed to the incomplete examinations. Others authors' observations contradict these statements; Khashab et al. reported that a higher proportion of ICs can be attributed to relatively longer colons in patients whose BMIs are $\leq 25$, and in women. ${ }^{5}$

Struijs et al. estimated the length of the LI as $122.4 \mathrm{~cm}$ in children aged 5 , or with a body mass of $20 \mathrm{~kg}$, or a body height of approx. $120 \mathrm{~cm}$. The LI gradually increases in length up to the age of 5; from then on, LI length does not increase significantly. According to those authors, the height of a child is the best factor for estimating the length of the LI. ${ }^{3}$

We agree that a colonoscopist's experience is one of the most significant factors affecting the success of the examination. ${ }^{29,30}$ We also share the prevailing view that the entire endoscopic team should exclusively perform pediatric endoscopies. ${ }^{31}$ As far as complications are concerned, we observed only minor bleeding in individual cases. Other studies confirm that the examination is safe (a complication rate of less than 1\%). ${ }^{12,22,23}$ Previous papers have described difficulties associated with the examination in patients who have undergone prior surgery, especially in the lesser pelvis. These difficulties primarily resulted from SC immobilization and a higher number of SC flexures. ${ }^{4}$ A small proportion of our patients had a history of surgery, usually involving partial resections of the ileocecal valve with end-to-end anastomosis, which had no significant effect on the examinations.

Thakkar et al. reported that up to $15 \%$ of colonoscopies do not reach the cecum. ${ }^{12}$ Our results are similar.

Our study had certain limitations. There were difficulties associated with the analysis of ICs and IACs; we were unable to predict the course of a colonoscopy in subsequent LI segments (whether the examination would be complete or whether it would come to an end at the next CP). Also, the study was limited to a specific group of children; the majority of them suffered from IBD, but the examinations were not carried out during active phases of the disease.

\section{Conclusions}

Based on the results of our study, the following conclusions may be drawn: 1 . Patients weighing up to $30 \mathrm{~kg}$ are highly prone to incomplete colonoscopies due to the specific anatomy of the LI. 2. Anatomy-related colonoscopy incompletion did not significantly correlate with the height and/or age of the patients. 3. The ICAR and MICAR are useful in predicting LI anatomy-related non-completion of colonoscopies and in presenting the risk to the patients' parents in an easily comprehensible way. 


\section{References}

1. Bourgouin $\mathrm{S}$, Bège $\mathrm{T}$, Lalonde $\mathrm{N}$, et al. Three-dimensional determination of variability in colon anatomy: Applications for numerical modeling of the intestine. J Surg Res. 2012;178(1):172-180.

2. Eickhoff A, Pickhardt PJ, Hartmann D, Riemann JF. Colon anatomy based on CT colonography and fluoroscopy: Impact on looping, straightening and ancillary maneuvers in colonoscopy. Dig Liver Dis. 2010;42(4):291-296.

3. Struijs M-C, Diamond IR, de Silva N, Wales PW. Establishing norms for intestinal length in children. J Pediatr Surg. 2009;44(5):933-938.

4. Hanson ME, Pickhardt PJ, Kim DH, Pfau PR. Anatomic factors predic tive of incomplete colonoscopy based on findings at CT colonography. AJR Am J Roentgenol. 2007;189(4):774-779.

5. Khashab MA, Pickhardt PJ, Kim DH, Rex DK. Colorectal anatomy in adults at computed tomography colonography: Normal distribution and the effect of age, sex, and body mass index. Endoscopy. 2009;41(8):674-678.

6. Alazmani A, Hood A, Jayne D, Neville A, Culmer P. Quantitative assessment of colorectal morphology: Implications for robotic colonoscopy. Med Eng Phys. 2016;38(2):148-154.

7. Punwani S, Halligan S, Tolan D, Taylor SA, Hawkes D. Quantitative assessment of colonic movement between prone and supine patient positions during CT colonography. Br J Radiol. 2009;82(978):475-481.

8. Spada C, Hassan C, Barbaro B, et al. Colon capsule versus CT colonography in patients with incomplete colonoscopy: A prospective, comparative trial. Gut. 2015;64(2):272-281.

9. Brenner $\mathrm{H}, \mathrm{Chang}-\mathrm{Claude} J$, Jansen L, Seiler CM, Hoffmeister M. Role of colonoscopy and polyp characteristics in colorectal cancer after colonoscopic polyp detection: A population-based case-control study. Ann Intern Med. 2012;157(4):225-232.

10. Kamiński M, Hassan C, Bisschops R, et al. Advanced imaging for detection and differentiation of colorectal neoplasia: European Society of Gastrointestinal Endoscopy (ESGE) Guideline. Endoscopy. 2014; 46(5):435-457.

11. Rees CJ, Rajasekhar PT, Rutter MD, Dekker E. Quality in colonoscopy: European perspectives and practice. Expert Rev Gastroenterol Hepatol. 2014;8(1):29-47.

12. Thakkar K, Holub JL, Gilger MA, et al. Quality indicators for pediatric colonoscopy: Results from a multicenter consortium. Gastrointest Endosc. 2016;83(3):533-541.

13. Niv Y, Hazazi R, Levi Z, Fraser G. Screening colonoscopy for colorectal cancer in asymptomatic people: A meta-analysis. Dig Dis Sci. 2008; 53(12):3049-3054.

14. Rathgaber SW, Wick TM. Colonoscopy completion and complication rates in a community gastroenterology practice. Gastrointest Endosc. 2006;64(4):556-562.

15. Gawron AJ, Veerappan A, McCarthy ST, Kankanala V, Keswani RN Impact of an incomplete colonoscopy referral program on recommendations after incomplete colonoscopy. Dig Dis Sci. 2013;58(7): 1849-1855.
16. Morini S, Zullo A, Hassan C, Lorenzetti R, Campo SMA. Endoscopic management of failed colonoscopy in clinical practice: To change endoscopist, instrument, or both? Int J Colorectal Dis. 2011:26(1): 103-108.

17. Wehrmann T, Lechowicz I, Martchenko K, Riphaus A. Routine colonoscopy with a standard gastroscope. A randomized comparative trial in a Western population. Int J Colorectal Dis. 2008;23(4):443-446.

18. Chung GE, Lim SH, Yang SY, et al. Factors that determine prolonged cecal intubation time during colonoscopy: Impact of visceral adipose tissue. Scand J Gastroenterol. 2014:49(10):1261-1267.

19. Hsieh Y-H, Kuo C-S, Tseng K-C, Lin H-J. Factors that predict cecal insertion time during sedated colonoscopy: The role of waist circumference. J Gastroenterol. 2008;23(2):215-217.

20. Nagata N, Sakamoto K, Arai T, et al. Predictors for cecal insertion time: The impact of abdominal visceral fat measured by computed tomography. Dis Colon Rectum. 2014;57(10):1213-1219.

21. Shah HA, Paszat LF, Saskin R, Stukel TA, Rabeneck L. Factors associated with incomplete colonoscopy: A population-based study. Gastroenterology. 2007;132(7):2297-2303.

22. Iqbal CW, Askegard-Giesmann JR, Pham TH, Ishitani MB, Moir CR. Pediatric endoscopic injuries: Incidence, management, and outcomes. J Pediatr Surg. 2008;43(5):911-915.

23. Tringali A, Balassone V, De Angelis $P$, Landi R. Complications in pediatric endoscopy. Best Pract Res Clin Gastroenterol. 2016;30(5):825-839.

24. Madiba TE, Haffajee MR. Sigmoid colon morphology in the population groups of Durban, South Africa, with special reference to sigmoid volvulus. Clin Anat. 2011;24(4):441-453.

25. Madiba TE, Haffajee MR, Sikhosana MH. Radiological anatomy of the sigmoid colon. Surg Radiol Anat. 2008;30(5):409-415.

26. Sadahiro S, Ohmura T, Yamada Y, Saito T, Taki Y. Analysis of length and surface area of each segment of the large intestine according to age, sex and physique. Surg Radiol Anat. 1992;14(3):251-257.

27. Phillips M, Patel A, Meredith P, Will O, Brassett C. Segmental colonic length and mobility. Ann R Coll Surg Engl. 2015;97(6):439-444.

28. Krishnan P, Sofi AA, Dempsey R, Alaradi O, Nawras A. Body mass index predicts cecal insertion time: The higher, the better. Dig Endosc. 2012; 24(6):439-442.

29. Franciosi JP, Mascarenhas M, Semeao E, Flick J, Kelly J, Mamula P. Randomised controlled trial of paediatric magnetic positioning device assisted colonoscopy: A pilot and feasibility study. Dig Liver Dis. 2009; 41(2):123-126.

30. Holme Ö, Höie O, Matre J, et al. Magnetic endoscopic imaging versus standard colonoscopy in a routine colonoscopy setting: A randomized, controlled trial. Gastrointest Endosc. 2011;73(6):1215-1222.

31. Lightdale JR, Acosta R, Shergill AK, et al; ASGE Standards of Practice Committee; American Society for Gastrointestinal Endoscopy. Modifications in endoscopic practice for pediatric patients. Gastrointest Endosc. 2014;79(5):699-710. 